\title{
RESEARCH ISSUES AND DEVELOPMENT IN Advance Manufacturing Systems
}

\author{
MAHENDRAKAR, S.R
}

Abstract: The last few decades have observed the intense global competition, increasing demand of variety of products, reduced product life cycles, fast technological development and also difficulty in assessing of prediction the demand accurately. To be profitable and competitive, the industry has to be quick to respond to the fast fluctuating world in which, emerging economies, new concepts and philosophies of doing business, technical developments and ever varying needs of customers pose serious challenges to its survival. This research focuses the various types of manufacturing systems like dedicated manufacturing system (DMS), flexible manufacturing system (FMS), lean manufacturing system (LMS) and reconfigurable manufacturing system (RMS). In the present work the limitations of the manufacturing system, various research and development issues related to advance manufacturing system have been discussed.

Key words: Dedicated manufacturing system (DMS), flexible manufacturing system (FMS), lean manufacturing system (LMS), reconfigurable manufacturing system (RMS), and research issues
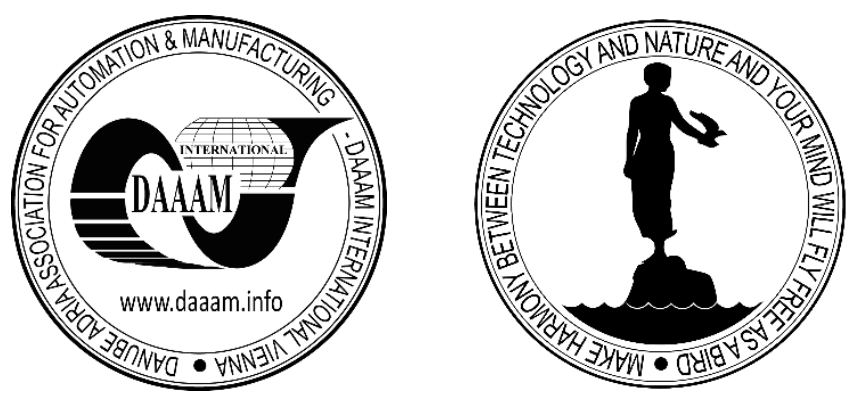

Authors' data: Asst. Prof. Mahendrakar, S[harmila] R[ao]*, *Mechanical Engineering Department, Chandigarh College of Engineering and Technology, Chandigarh,India, msharmila1206@gmail.com

This Publication has to be referred as: Mahendrakar, S[harmila] (2018). Research Issues and Development in Advance Manufacturing Systems, Chapter 13 in DAAAM International Scientific Book 2018, pp.141-152, B. Katalinic (Ed.), Published by DAAAM International, ISBN 978-3-902734-19-8, ISSN 1726-9687, Vienna, Austria DOI: $10.2507 /$ daaam.scibook.2018.13 


\section{Introduction}

The previous modern manufacturing scenario people observed suitable global competition, reduced product life cycles, increasing demand of variety of products, fast drastic development in manufacturing processes and also difficulty in assessing of forecast the demand accurately from present demand. (Mulc et al., 2015). To be competitive and profitable, the industry has to be quick to respond to the rapidly changing world in which, emerging economies, new concepts and philosophies of doing business, technical developments and ever changing needs of customers pose serious challenges to its survival.

Because of this the manufacturing systems have been drastically changing over the period of time, which is a continuous process (Puik et al., 2017). To adjust with the current circumstances the industry requires the advance manufacturing system, which can offer broad range of product variety and capability to adjust quickly and economically (Setchi \& Lagos, 2004).

\subsection{An Overview of Manufacturing Systems}

Figure1 depicts a manufacturing system which is defined as a collection of integrated equipment and human resources, the basic function of which is to execute one or more processing and/or assembly tasks on a starting raw material, part or set of parts (Groover, 2001).

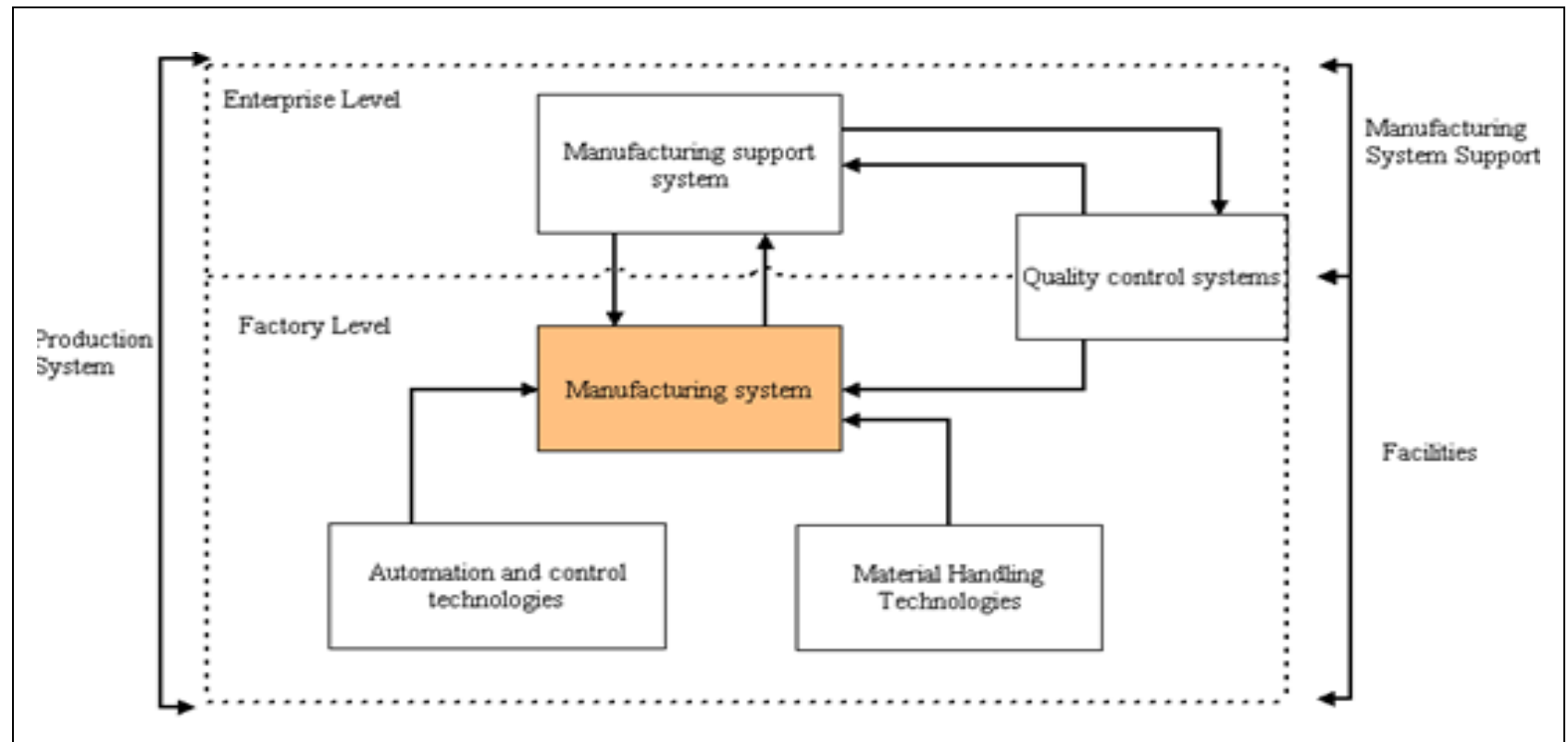

Fig. 1. Manufacturing system

The components of a manufacturing system include production machines and tools, fixtures and other related hardware, material handling system like automated guided vehicles AGVs, conveyors, pallet trucks, computer system to coordinate and control the above components and human workers. 


\subsection{Types of Manufacturing Systems}

There are different types of manufacturing systems that have evolved over the years to fulfil the customer requirement in a dynamic and competitive market. The manufacturing systems evolved over the course of last century are discussed below:

\subsubsection{Dedicated Manufacturing System (DMS)}

A manufacturing system designed for making of a specific part, and which uses transfer line technology with fixed tooling.These are based on fixed automation and manufacture company's core products or parts at high volume with less variety (Setchi and Lagos, 2004). Every single part (e.g., pump housing) are produced by each dedicated line.

\subsubsection{Flexible Manufacturing System (FMS)}

According to Kumar et al. (2003), "A manufacturing system configuration with fixed hardware and fixed, but programmable, software to handle variations in work orders, part-programs, production schedules, and tooling for various types of parts". FMS main aim is to execute the manufacturing of various parts in a cost effective manner with shortened changeover time which change overtime at the wanted volume and quality.

It consists of computer numerically controlled (CNC) machines and other programmable automation which can produce a variety of products on the same system. Table 1 shows the features of DMS and FMS systems. The production capacity of FMS's is usually lower than that of dedicated lines and their initial cost is higher (El Maraghy, 2006; Youssef and El Maraghy, 2007).

\begin{tabular}{|l|l|}
\hline & Fixed Hardware \\
\hline No Software & Dedicated Manufacturing Lines \\
\hline Fixed Software & FMS \\
\hline
\end{tabular}

Tab. 1. Features of DMS and FMS

\subsubsection{Lean Manufacturing System (LMS)}

Lean manufacturing suggests many tools, which can assist in making the value to a customer in a simpler way. Some of the most broadly used tools are value stream mapping (VSM), total productive maintenance (TPM), Just in time JIT, 5S, and Kaizen (Mehrabi et al., 2002).

\subsubsection{Value Stream Mapping}

Value stream mapping is also known as VSM. It is one of the most successful tools of lean manufacturing. VSM mainly focuses the stream of the value and seeks to find the areas of improvement (Mittal and Verma, 2016). VSM focuses on value in the framework of what the customer is willing to pay not for the wastes generated by the organization. 
The main objective of VSM is to find the lead-time associated with a certain product flow throughout a system. The whole process of VSM can be divided into four key steps: (1) identify the family of products, (2) generate a current state value stream map, (3) suggests a future state value stream map, and (4) create an action plan (Kumar et al., 2003).

\subsubsection{Current Value Stream Map (CVSM)}

Data collection for the material flow started from despatch department, and worked backward all the way to the moulding process, gathering snapshot data such as inventory levels before each process, process cycle times (CTs),number of operators, and changeover times (COT) (Seth and Gupta, 2005; Serrano et al., 2008; Singh et al., 2011).

Figure 2 shows the current state map that was constructed, the small boxes in the current value stream map represent the process and the number inside the box is the number of workers at each process. Also, each process has a data box below, which contains the process $\mathrm{CT}$, the number of shifts, and the COT.

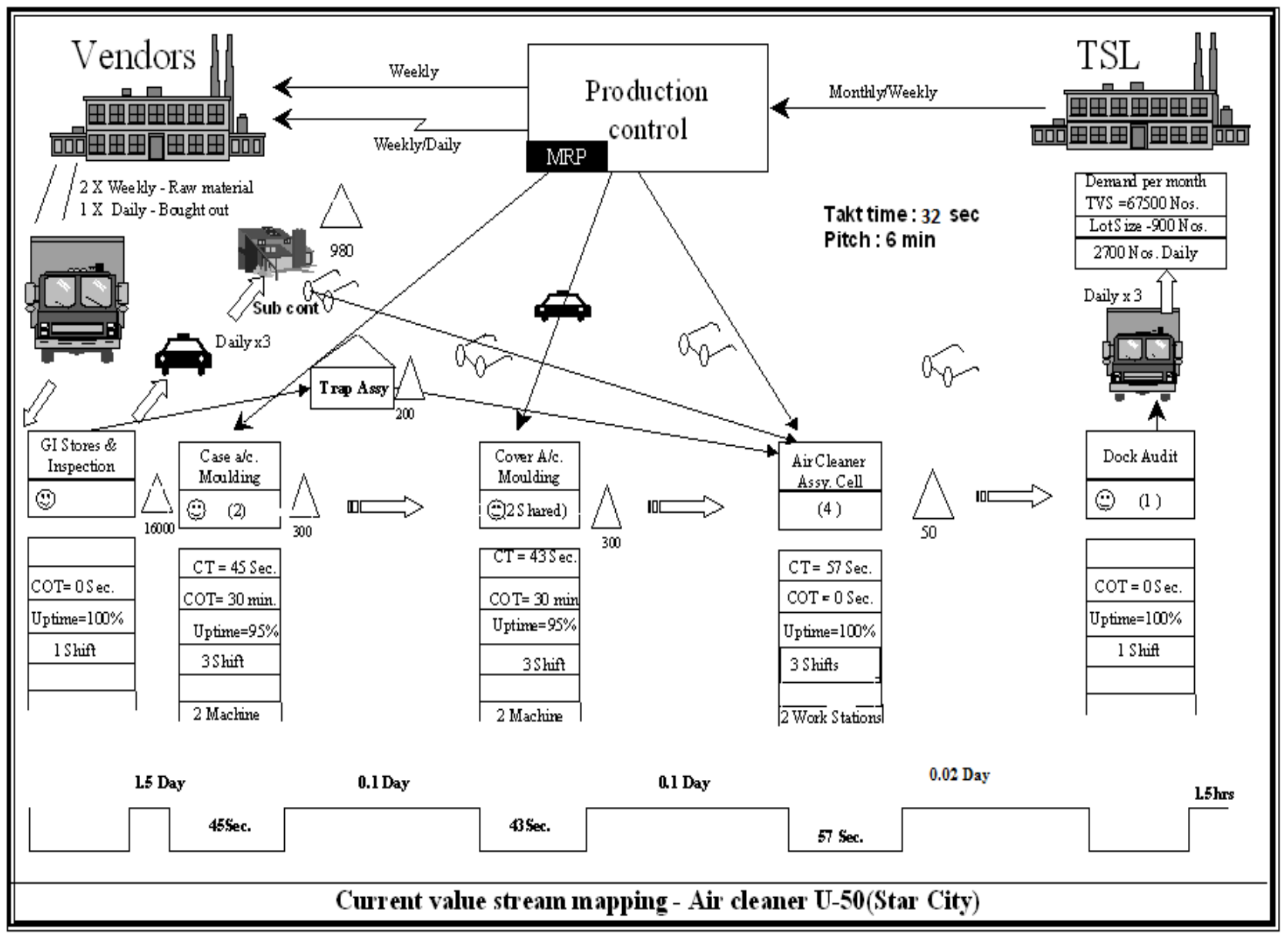

Fig. 2. Current Value Stream Map 
After taking all the information and material flows, they are connected as indicated by arrows in the map, demonstrating how each workstation receives its schedule from material requirement planning department.

\subsubsection{Future Value Stream Map (FVSM)}

The following parameters should be considered while drawing the future value stream map or lean map (Ghosh,2013).

-Production should be followed according to Takt time.

-Developing continuous flow wherever possible.

In future state map warehouse inventory is eliminated by sending the assembly directly to the trucks.

Since U-50 air cleaner hourly requirement is 50 from each work station, a supermarket is installed to hold the inventory of 1hour.whenevr customer requires air cleaner, its withdrawal Kanban will be given to the material handler (part feeder) to withdraw 1 hour equal of air cleaner from air assembly.

When material handler removes 1-hour inventory from supermarket, a withdrawal Kanban will be sent back to the moulding machine as shown in Figure 3.

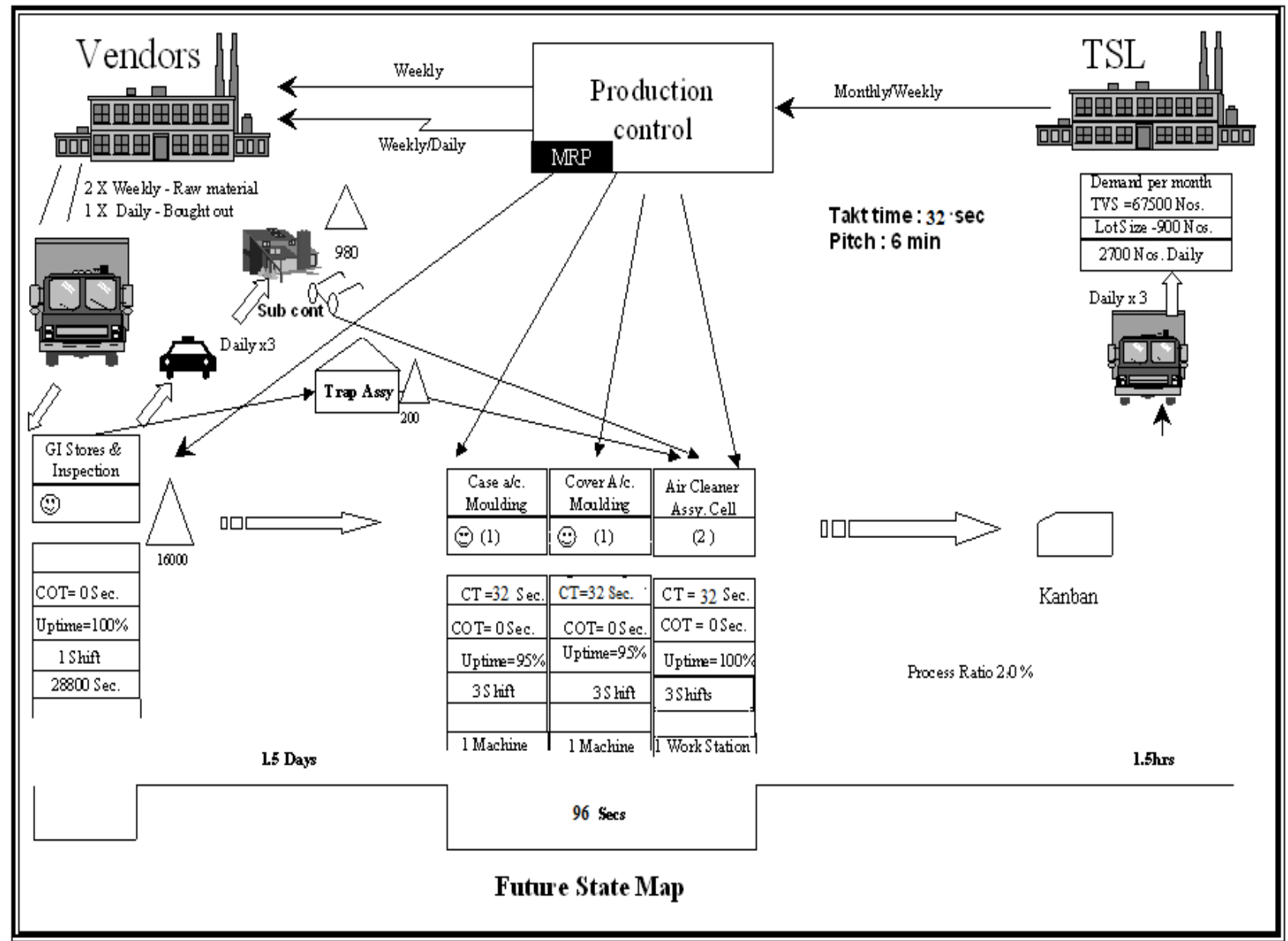

Fig. 3. Future Value Stream Map 
Mahendrakar, S.: Research Issues and Development in Advance Manufacturing Sy...

\subsubsection{Just in time (JIT)}

The aim of JIT is to keep the level of inventory to a smallest amount. This is achieved by permitting each operation to pull the objects from the precedential operation rather than pushing objects in the production system.

\subsubsection{Kaizen}

Kaizenmeans constant improvement. The surroundings is created at the work centre that enthusiasts people engaged in the day-to-day work to make the method of work more productive or better by continuously improving it.

\section{The Changing Manufacturing Environment}

With time new market conditions have come up for medium and high-volume manufacturers characterized by: (i) short windows of opportunity for new products, and (ii) large fluctuations in product demand. To cope with the need for quick introduction of products, computer-aided design (CAD) and concurrent engineering methods have dramatically reduced product development times during the last decade.

Notable examples include the design of the Boeing 777 and the Chrysler Neon. The lead time of production system (i.e., the time to design and build the production system, and to ramp-up to full-volume, high-quality production) is today's bottleneck. Reducing lead time for manufacturing systems that produce the new products provides major economic savings and is the critical objective for responding to short windows of opportunity.

The other challenge-coping with large fluctuations in product demand - can be theoretically solved by utilizing flexible manufacturing systems (FMSs) that have the ability to produce a variety of products. However two thirds of the manufacturers are not satisfied with FMSs performance. Reasons attribute to it are: (i) FMS is expensive, (ii) it utilizes inadequate system software since developing user-specific software is extremely expensive and (iii) the systems are subject to rapid obsolescence (Koren and Ulsoy, 1997; Mehrabi et al., 2002; Mittal et al., 2017).

Addressing these limitations as well as the new market conditions require advance manufacturing system that enables:

1) The launch of new product models to be undertaken very quickly, 2) Addition of incremental manufacturing capacity as the market grows and 3) New developments in manufacturing technology to be utilized in production. In Figure $4 \mathrm{AB}, \mathrm{CD}$ and $\mathrm{EF}$ are the past, present and future status of product variety of different type of manufacturing system over a period of time. GH represents the gap between market demands and the present manufacturing system.

Dedicated-rigid manufacturing lines (DMLs) cannot adapt to variations in market whereas flexible manufacturing systems can adapt to variations in demand at some extent. 
A reconfiguration link is needed to bridge the gap between capacity and functionality of manufacturing systems and dynamic market demands. The major role of the reconfiguration link are to club products having similar demands and choose the suitable families, which can be efficiently manufactured in an RMS design over reconfiguration stages.

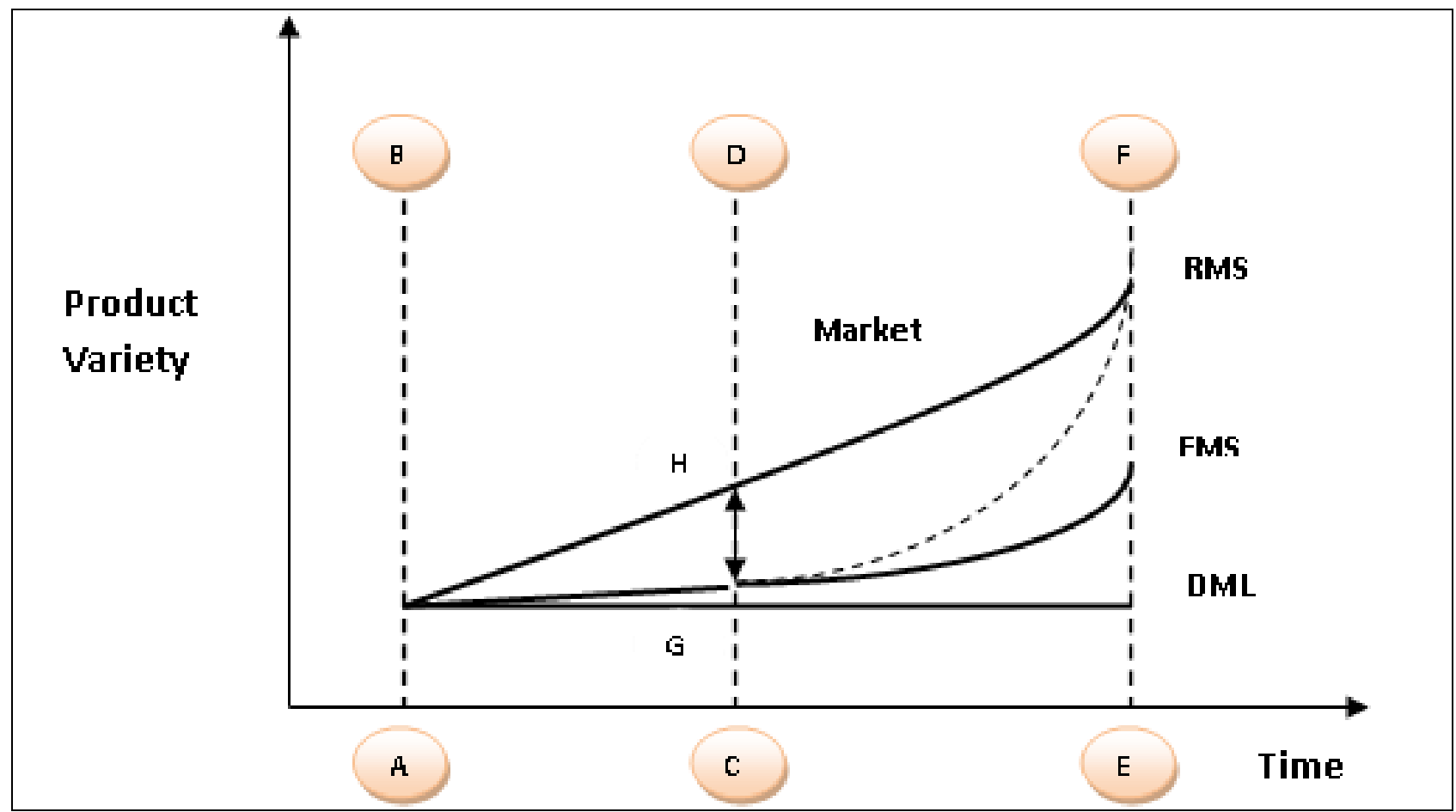

Fig. 4. Effects of changes in market demand on manufacturing systems over time

\section{Reconfigurable Manufacturing System (RMS)}

According to Mehrabi et al. (2002), "Reconfigurable Manufacturing System (RMS) an advance manufacturing system is designed for rapid change in structure, hardware and software components for adjusting production capacity and functionality in part family.

The reconfiguration process will prove lengthy and costly if the system and its machines are not designed at the outset for reconfigurability and so the system becomes impractical" (Koren \& Ulsoy, 1997).

Reconfigurable manufacturing systems, whose components are reconfigurable machines and reconfigurable controllers, as well as methodologies for their systematic design and diagnostics, are the cornerstones of this new manufacturing paradigm. For an entire production system components are conveyors, machines, mechanisms for individual machines, new controller algorithms and new sensors.

New conditions in existing manufacturing systems change product demand, produce a new product, or integrate new process technology (Youssef and El Maraghy, 2006 a - 2006 b). 
Mahendrakar, S.: Research Issues and Development in Advance Manufacturing Sy...

\section{RMS:Major Research and Development Issues}

RMS being the most promising technology and with its features it has inbuilt capabilities for capacity adjustment, product variety and shorter reconfiguration time. RMS requires research and development in certain key areas (Koren et al., 1998).

- Research and Development Issues Associated to Design at System Level

- Research and Development Issues Associated to Design at Machine level

- Research and Development Issues Associated to Ramp-up Time Reduction

\subsection{Research and Development Issues Associated to Design at System Level}

The reconfigurable manufacturing system is designed by accepting systematic approach, carried by software tools that map the product features to modules of processing units and yield a system layout/configuration and process plan, which fits the customer needs.

The configuration of the system is identified with respect to the part or part family to be produced with the desired mix and production volume. The important research issues on the system level design are as follows:

- Development of a systematic approach for design of RMS at the system level.

- Analysis of the impact of system configurations on reliability, maintainability, cost and quality.

- Analysis and design of full process from identifying customer needs through operation selection and system configuration selection etc.

- Economic analysis of various system configurations and their selection.

\subsection{Research and Development Issues Associated to Design at Machine Level}

Reconfigurable manufacturing systems are designed at both the system and machine levels for the competent functioning. As discussed, to support reconfiguration and ramp-up the design must be integrable, modular, customized, and diagnosable.

An open-architecture controller and Modular machine component design are main enabling technologies. However, methods are to be developed for the quick and efficient reuse of such modules for achieving reconfigurability. Machine components (e.g., slideways, spindles, drives) and controller components (e.g., servo control, temperature control) must be systematically maintained and stored for reuse, and the new modules added should be immediately updated in the module library.

The control module needed for the application are chosen and then configured to integrate them for the chosen machine and automatically check its real time constraints. Some of the research issues on the machine level design are listed below:

- To generate reconfigurable machines for the required manufacturing tasks/operations.

- Development of systematic algorithms and fundamental approaches for the design and analysis of reconfigurable machines along with their controllers.

- Design and development of RMTs, their modular units and open architecture controllers. 


\subsection{Research and Development Issues Associated to Ramp- up Time Reduction}

As the RMS gets reconfigured each time, the production system must be adjusted before it achieves the consistency in achieving the required production rate and desired quality. This is known as ramp-up, which may take as long as months in the traditional manufacturing systems (Rakyta et al., 2016).

The goal of RMS is the responsiveness, therefore the studies related to the ramp up time reduction are very essential. Following are the key areas related to the ramp up time reduction:

- Methodology to be adopted at the system level and machine level to reduce the ramp up time.

- Developing the logical approaches to analyze the root cause of the component failure, along with the quality and process variations.

\section{Limitations and Future Scope}

The limitations of the research are not limited to DMS FMS LMS only, but it can be further extended to RMS and advanced RMS methods. Future research plans may be extended RMS, extended RMS with cellular manufacturing and RMS with concurrent engineering technology (CET) can be explored. The present research will lead to advanced RMS and FMS. The further improvement in next step would be RMS with group technology (GT) and RMS cellular manufacturing (CM) (Singh et al., 2011).

\section{Conclusions}

The present work describes the manufacturing system, types of different manufacturing system, effects of changes in market demand on manufacturing systems over time, need of advance manufacturing system i.e. reconfigurable manufacturing system and various issues related to RMS. The present research work explains the comprehensive approach for the rapid response of the RMS. It can further lead to advanced manufacturing approaches which scopes in near scenario sector.

\section{References}

ElMaraghy, H.A. (2006). Flexible and reconfigurable manufacturing systems paradigms. International Journal of Flexible Manufacturing Systems, 17, No. 4, 261276.

Ghosh, M. (2013).Lean manufacturing performance in Indian manufacturing plants.Journal of Manufacturing Technology Management, 24, No. 1, 113-122.

Groover, M.P. (2001). Automation, Production systems, and Computer Integrated Manufacturing. Pearson Education Asia, $\mathrm{I}^{\text {st }}$ Indian edition.

Koren, Y. \& Ulsoy, A.G. (1997). Reconfigurable Manufacturing Systems, Engineering Research Center for Reconfigurable Machining Systems(ERC/RMS) Report \# 1, The University of Michigan, Ann Arbor.

Koren, Y.; Hu, S.J. \& Weber, T.W. (1998). Impact of manufacturing system configuration on Performance. CIRP Ann., 47, No. 1, 369-372. 
Kumar, R., Tiwari, M.K. \& Shankar, R. (2003). Scheduling of flexible manufacturing systems: an ant colony optimization approach. Proceedings of the Institution of Mechanical Engineers, Part B: Journal of Engineering Manufacture, 217, No. 10, 1443-1453.

Mehrabi, M.G., Ulsoy, A.G., Koren, Y. \& Heytler, P. (2002). Trends and perspectives in flexible and reconfigurable manufacturing systems. Journal of Intelligent Manufacturing, 13, No. 2, 135-146.

Mittal, K.K. \& Verma V. (2016). Lean manufacturing system for air cleaner assembly cell. Int. J. of Logistics Systems and Management, 23, No.3, 314-328.

Mittal, K.K., Jain, P.K. \& Kumar, D. (2017). Configuration Selection in Reconfigurable Manufacturing System Based on Reconfigurability. International Journal of Logistics Systems and Management, 27, No.3, 363-379.

Mulc, T., Udiljak, T. \& Ciglar, D.(2015). Structure of Reconfigurable Manufacturing Systems, DAAAM International Scientific Book 2015, ISBN 978-3-902734-05-1, ISSN 1726-9687, Vienna, Austria, 369-390.

Puik, E., Telgen, D., Moergestel, L. \& Ceglarek, D. (2017). Assessment of reconfiguration schemes for Reconfigurable Manufacturing Systems based on resources and lead time. Robotics and Computer-Integrated Manufacturing, 43, 3038.

Rakyta, M., Fusko, M., Haluska, M. \& Grznar, P. (2016). Maintenance Support System for Reconfigurable Manufacturing Systems, Proceedings of the 26th DAAAM International Symposium, ISBN 978-3-902734-07-5, ISSN 1726-9679, Vienna, Austria,1102-1108.

Serrano, I., Ochoa, C. \& Castro, R. (2008). Evaluation of value stream mapping in manufacturing system redesign. International Journal of Production Research, 46, No. $16,4409-4430$.

Setchi, R.M. \& Lagos, N. (2004). Reconfigurability and reconfigurable manufacturing system-State of the art review. INDIN-04, $2^{\text {nd }}$ IEEE International Conference on Industrial Informatics, Berlin, Germany, 529-535.

Seth, D. \& Gupta, V. (2005). Application of Value Stream Mapping for Lean Operations and Cycle Time Reduction: An Indian Case Study. Production Planning \& Control,16, No.1, 44-59.

Singh,B., Garg, S.K. \& Sharma, S.K. (2011). Value stream mapping: literature review and implication for Indian industry. International Journal of Advanced Manufacturing Technology, 53,No.5-8, 799-809.

Youssef, A.M.A. \& ElMaraghy, H.A. (2006 a). Modelling and optimization of multiple-aspect RMS configurations. International Journal of Production Research, 44, No.22, 4929-4958.

Youssef, A.M.A. \& ElMaraghy, H.A. (2006 b). Assessment of manufacturing systems reconfiguration smoothness. International Journal of Advanced Manufacturing Technology, 30, No. 1-2, 174-193.

Youssef, A.M.A. \& ElMaraghy, H.A. (2007). Optimal configuration selection for Reconfigurable Manufacturing Systems. International Journal of Flexible Manufacturing Systems, 19, No. 2, 67-106. 